\section{In-hospital adverse drug events: analysis of trend in Portuguese public hospitals}

\author{
Eventos adversos a medicamentos durante a \\ internação hospitalar: análise de tendência \\ em hospitais públicos de Portugal
}

\section{Eventos adversos con medicamentos dentro de hospitales: análisis de tendencia en hospitales públicos portugueses}

\author{
Mavilde Vitorino 1, \\ Pedro Aguiar 2,3 \\ Paulo Sousa 2,3
}

\begin{abstract}
The objectives of this study were to analyze in-hospital adverse drug events (ADEs) in Portuguese public hospitals, and their association with mortality and the duration of hospitalization. We analyzed an administrative database containing the registration of all hospitalizations occurring in Portuguese public hospitals in 2013-2015. ADEs were identified using the codes E850-858.9 and E930-949.9 from ICD-9-CM. We identified all episodes with registration of in-hospital $A D E$ and we compared them with a random sample of an equal number of episodes with no events recorded. A total of 3,041,443 cases were analyzed, 60,521 presented at least one ADE from which 17,213 occurred in hospital context. The most frequent drug classes associated with ADE were the antineoplastics/immunosuppressant drugs, antibiotics and steroids. Patient characteristics associated with a greater occurrence of in-hospital ADEs (all with $p<0.001)$ were medical admissions $(O R=1.29)$, the diagnosis - myeloid leukaemia $(O R=18.63)$, nephrotic syndrome $(O R=15.75)$, pneumonia $(O R=1.33)-$, a higher number of secondary diagnoses $(O R=1.27)$, and increased duration of hospital stay $(O R=1.06)$. Hospitalizations with records of in-hospital ADEs presented a significantly higher mortality (9.6\% vs. 4.5) and duration of hospitalization (22.6 vs. 6.4 days). ADEs were shown to be directly associated with an increase in the duration of hospital stay of 8.18 days. This study adds some interesting insights related to the most frequent drug classes and patient characteristics that can influence the frequency of ADEs in Portuguese public hospitals and also the burden of injury resulting from them.
\end{abstract}

Adverse Event; International Classification of Diseases; Hospitalization 


\section{Introduction}

An adverse drug event (ADE) is defined by the World Health Organization (WHO) as a harmful and involuntary harm arising from the use of a drug and which occurs due to preventive health care administered to the patient for diagnosis, therapy, or the modification of physiological functions 1. This definition comprises adverse drug reaction (ADR) and accidental poisoning by drugs (AP), as long as these result in harm.

ADEs are one of the main concerns regarding the patient's safety, because they represent one of the most frequent worldwide causes of harm, the main consequence of which is the death of thousands of patients per year 2. To address these problems, WHO launched the third Global Patient Safety Challenge, Medication Without Harm, with the overall goal "to reduce medication errors by 50\% in the next five years" 2 .

International studies show that between $0.7 \%$ and $21.3 \%$ of hospitalized patients have an ADE 3,4,5,6,7. These events, besides significantly impacting mortality and morbidity, are also associated with an increase in health costs 5,8. On a global level, annual costs have been estimated at 42 billion dollars, representing approximately $1 \%$ of total health expenses 2.

In Portugal, the evidence available also points to a high rate of in-hospital ADEs. A study carried out in nine acute care public hospital centers, using the clinical record review methodology, identified an incidence of $12.5 \%$ adverse events in the year 2013 , of which $9.8 \%$ were associated with drug errors, representing the third most frequent adverse event 9 . According to other studies carried out in Portuguese public hospitals, using administrative data, $1.46 \%$ and $1.88 \%$ of hospitalized patients showed at least one ADE 10,11.

Given the previously mentioned facts, it becomes apparent that studies carried out in hospitals in a diverse range of countries have identified a high ADE frequency, with significant heterogeneity. As many of these events could be prevented, there is a growing interest in their effective identification and the implementation of successful preventive strategies, with the aim of improving patient safety and enhancing hospital efficiency 4 . The assessment of the clinical performance from health services and organizations is essential to move towards care quality excellence and to achieve a more efficient performance 12 .

Adverse event frequency has been calculated based on different methodologies, using various data sources, including clinical record review, direct observation, analysis of incidents by reporting systems, systems based on administrative data, among others 13 .

The use of administrative data, based on the International Classification of Diseases (ICD), as a support to monitoring adverse events occurring during hospitalization (in-hospital events) has gained increasing relevance in the past decade, because it requires less resources - economic and human, among others - and is readily available 14 .

Nevertheless, analysis of adverse events through administrative data may detect events which have occurred before admission to hospital. The application of "present at admission" (PAA) coding has enabled a more reliable analysis of the adverse events occurring on the in-hospital stage, because it allows differentiation between the events present at the date of admission at hospital and the ones acquired during hospitalization ${ }^{15}$. In this regard, it is important to emphasize that the PAA indicator was not contemplated in previous studies carried out in Portugal, based on administrative data.

Therefore, the underlying reasons motivating this study are as follows: in-hospital ADEs are clinically and economically relevant, the dimension of these adverse events in Portugal based on the PAA indicator is not yet known, and the authors are convinced that it is only possible to implement measures to improve the quality of the healthcare provided and to contribute to a greater efficiency of Portuguese hospitals if the adverse event dimension and its impacts are known.

In this regard, the objective we have defined for this study is to analyze ADEs which have occurred within the in-hospital period, and their impact on mortality and duration of hospitalization, from 2013-2015, after PAA indicators were introduced. 


\section{Methods}

\section{Type of study}

A retrospective observational cross-sectional study was carried out, using administrative data from all Portuguese public hospitals.

\section{Data sources}

We used the Portuguese hospital morbidity database (BDMH) for the 2013-2015 triennium. The selection of this period is due to the fact that the PAA indicator was only introduced into the BDMH's clinical encoding in 2013. The years 2016, 2017 and 2018 were also not considered because, at the date of completion of this study, there was no final validation of the data available for these years.

This database aggregates data from all hospitalizations and outpatient episodes occurring in Portuguese national health system hospitals, encoded in accordance with the ICD, 9th Revision, Clinical Modification (ICD-9-CM) and classified into diagnosis related groups. The ICD-10 has been used in Portuguese hospitals since 2017. For that reason, in this study, we used the ICD-9.

The criteria for the selection of the ADE codes were based on the literature analyzed 10,16,17,18. The in-hospital ADEs were identified on the BDMH using the E850-858.9 codes (50 codes) for AP and E930-949.9 codes (171 codes) for ADRs which were not present at the moment of admission. The application of the variable encoded PAA allowed us to differentiate the ADEs that were already present at the moment of admission in hospital from the ones acquired during the hospitalization.

The set of official data in this database was previously anonymized, thus waiving the need for informed consent and authorization from the ethics committee.

\section{Statistical analyses}

In a first stage, the episodes with at least one ADE occurring during hospitalization (in-hospital) were identified for the whole population under study. After that, we calculated the in-hospital ADE frequency associated with $\mathrm{ADR}$ and $\mathrm{AP}$ and identified the class of drugs most frequently associated with these events. In this stage, we included descriptive statistical measurements (absolute and relative frequencies mean).

In the second stage, we compared the in-hospital ADE episodes with a random sample of an equal number of episodes with no events recorded, with regard to the population's characteristics, mortality, and the duration of stay at hospital. At first, a bivariable analysis was carried out, with the variables: age, gender, type of hospital admission (urgent vs. planned), type of treatment (surgical vs. medical), the most frequent six diagnoses for in-hospital ADE episodes, the number of secondary diagnoses, and the duration of stay. At this stage, in the bivariable analysis, we used Fisher's exact test, the chisquare test of independence, when comparing qualitative variables and Student's t-distribution test for independent samples when comparing two groups of quantitative dependent variables. The statistically significant variables $(\mathrm{p}<0.05)$ were included in the multivariable analysis.

To identify the characteristics of the population associated with the occurrence of in-hospital ADEs and to analyze the association of these events with mortality, we opted for a binary logistic regression analysis.

To assess the association of in-hospital ADE events with duration of stay, we opted for a multiple linear regression analysis.

The multivariable analysis results were displayed as odds ratio (OR) in the logistic regression and as a non-standard regression coefficient (B) in the linear regression with $95 \%$ confidence intervals ( $95 \% \mathrm{CI})$. Values of $\mathrm{p}<0.05$ were deemed statistically significant.

The statistical analysis was carried out using SPSS for Windows, version 25.0 (https://www. ibm.com/). 


\section{Results}

Analysis of 3,041,443 episodes of patients hospitalized in Portuguese public hospitals for the period of 2013-2015 were carried out (Table 1). From these, 60,521 (2\%) suffered from at least one ADE, of which $28.5 \%(17,213$; $0.6 \%$ of the total episodes) occurred within the in-hospital framework. In-hospital ADE episodes increased gradually throughout the triennium, from $0.41 \%$ in 2013 to $0.65 \%$ in 2015 .

Table 1 shows some descriptive statistics of the whole population and the total frequency of inhospital ADE distribution per age, gender, type of admission and treatment, principal diagnosis, and the mean number of secondary diagnoses.

The greatest proportion of in-hospital ADE episodes (54.9\%) occurred in patients aged 65 years or over.

The mean number of secondary diagnoses was much higher for in-hospital ADE episodes (11.7\% vs. $3.9 \%)$.

In certain episodes, several ADEs were recorded. Considering the multiple ADEs occurring for each episode, the total number of events detected was 70,244, from which 19,260 (27\%) were in-hospital.

\section{Table 1}

Descriptive statistics of the whole population and the total frequency of in-hospital adverse drug events (ADEs) distributions per age, gender, type of admission and treatment, principal diagnosis and the mean number of secondary diagnoses.

\begin{tabular}{|c|c|c|}
\hline & $\begin{array}{c}\text { Whole population } \\
\text { n (\%) }\end{array}$ & $\begin{array}{c}\text { In-hospital ADE } \\
\text { n (\%) }\end{array}$ \\
\hline Total & $3,041,443(100.0)$ & $17,213(0.6)$ \\
\hline \multicolumn{3}{|l|}{ Age (years) } \\
\hline$<65$ & $1,738,251(57.1)$ & $7,755(45.1)$ \\
\hline$\geq 65$ & $1,303,192(42.9)$ & $9,458(54.9)$ \\
\hline Mean age & 53.6 & 62 \\
\hline \multicolumn{3}{|l|}{ Gender } \\
\hline Male & $1,391,747(45.8)$ & $8,534(49.6)$ \\
\hline Female & $1,649,696(54.2)$ & $8,679(50.4)$ \\
\hline \multicolumn{3}{|c|}{ Type of hospital admission } \\
\hline Urgent & $1,815,567(59.7)$ & $12,590(73.1)$ \\
\hline Planned & $1,225,876(40.3)$ & 4,623 (26.9) \\
\hline \multicolumn{3}{|c|}{ Type of treatment } \\
\hline Surgical & $929,949(30.6)$ & $4,034(23.4)$ \\
\hline Medical & $2,111,494(69.4)$ & $13,179(76.6)$ \\
\hline \multicolumn{3}{|c|}{ Principal diagnosis * } \\
\hline 486 & $92,347(3.0)$ & $995(5.8)$ \\
\hline 581.1 & $22,627(0.7)$ & $699(4.1)$ \\
\hline 428.0 & $44,027(1.4)$ & $571(3.3)$ \\
\hline 20.500 & $2,299(0.1)$ & $462(2.7)$ \\
\hline 434.91 & $41,077(1.4)$ & $440(2.6)$ \\
\hline 038.9 & $20,657(0.7)$ & $311(1.8)$ \\
\hline \multicolumn{3}{|c|}{ Secondary diagnoses } \\
\hline Mean & 4.3 & 11.7 \\
\hline
\end{tabular}

* ICM-9-CM codes: 486 Pneumonia, organism unspecified; 581.1 Nephrotic syndrome with lesion of membranous glomerulonephritis; 428.0 Congestive heart failure, unspecified; 20.500 Acute myeloid leukaemia, without mention of having achieved remission; 434.91 Cerebral artery occlusion, unspecified with cerebral infarction; 038.9 Unspecified septicemia. 
Regarding the nature of in-hospital ADEs, 19,154 (99.4\%) were associated with ADR E-codes and 106 (0.6\%) with AP E-codes. Figures 1 and 2 illustrate the most frequent classes of drugs detected in in-hospital ADEs-ADR E-codes and AP E-codes, respectively.

To analyze the characteristics of the population associated with a higher incidence of in-hospital ADEs, as well as the association of these events with mortality and hospitalization duration, we compared in-hospital ADE episodes $(17,213)$ with a random sample of an equal number of episodes with no ADEs.

\section{Characteristics of the population associated with the occurrence of in-hospital ADEs}

Table 2 shows some descriptive statistics of the in-hospital ADE episodes $(17,213)$ and the random sample of an equal number of episodes with no ADEs. In these table, we also show the results of the bivariable and multivariable (multiple logistic regression) analyses, which aimed to identify patient characteristics independently associated with in-hospital ADEs.

In the bivariable analysis some patient characteristics with statistical significance $(\mathrm{p}<0.001)$ were associated with a large frequency of in-hospital ADEs: aged over 65 years, male, admissions coded as urgent, medical diagnostic-related group type, top six principal diagnoses, and a greater number of secondary diagnoses. In these analyses, we also observed that as the number of hospitalization days grew, so did the probability of occurrence of an in-hospital ADE.

In the multivariable analysis (multiple logistic regression) we observed that ages 65 or older did not show a greater probability for the occurrence of in-hospital ADEs (OR = 0.69; $\mathrm{p}<0.001)$. The characteristics observed in those patients showing a higher probability of in-hospital ADE occurrence were, independently, associated with medical treatments $(\mathrm{OR}=1.29$; $\mathrm{p}<0.001)$, main diagnoses - pneumonia, unspecified organism $(\mathrm{OR}=1.33$; $\mathrm{p}<0.001)$, nephrotic syndrome with lesion of membranous glomerulonephritis $(\mathrm{OR}=15.75 ; \mathrm{p}<0.001)$, acute myeloid leukaemia without mention of having achieved remission $(\mathrm{OR}=18.63 ; \mathrm{p}<0.001)-$, and a greater number of secondary diagnoses $(\mathrm{OR}=1.27 ; \mathrm{p}<0.001)$.

\section{Figure 1}

Distribution of five most frequent in-hospital adverse drug reactions (ADRs).

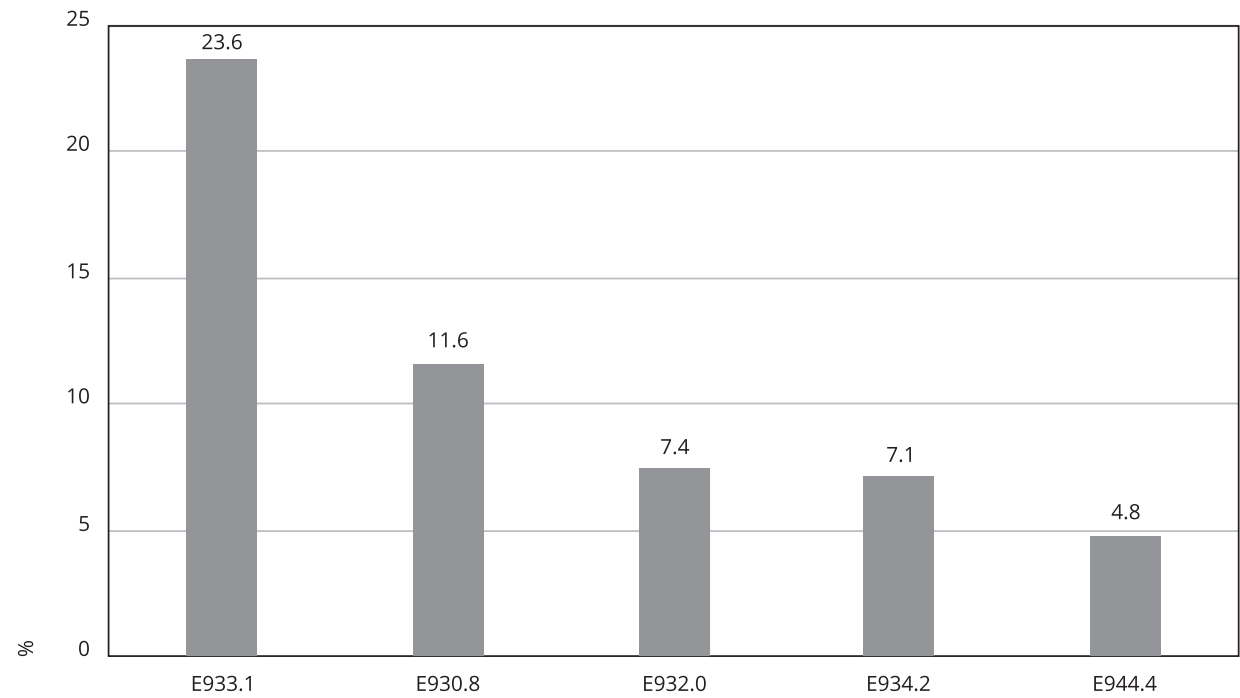

E933.1: Antineoplastic and immunosuppressive drugs causing adverse effects in therapeutic use; E930.8: Other specified antibiotics causing adverse effects in therapeutic use; E932.0: Adrenal cortical steroids causing adverse effects in therapeutic use; E934.2: Anticoagulants causing adverse effects in therapeutic use; E944.4: Other diuretics causing adverse effects in therapeutic use. 


\section{Figure 2}

Distribution of five most frequent in-hospital accidental poisoning by drugs (AP)

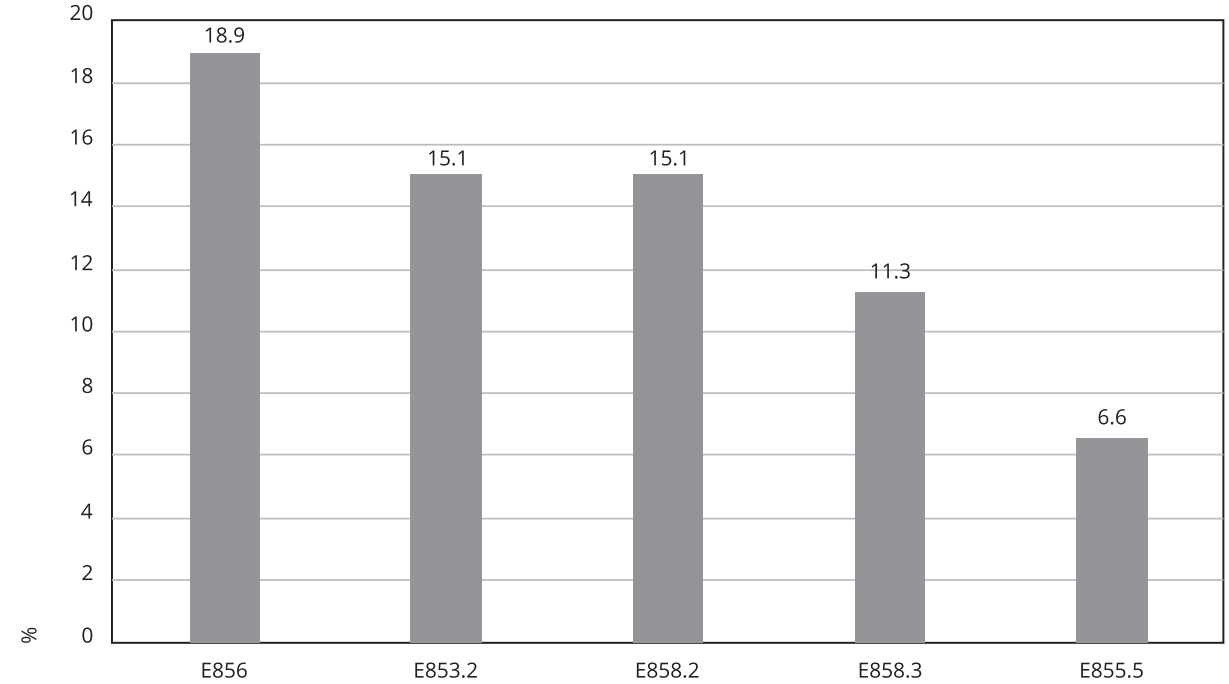

E856: Accidental poisoning by antibiotics; E853.2: Accidental poisoning by benzodiazepine-based tranquilizers; E858.2: Accidental poisoning by agents primarily affecting blood constituents; E858.3: Accidental poisoning by agents primarily affecting cardiovascular system; E855.5: Accidental poisoning by sympathomimetics [adrenergics].

Table 2

Bivariable and multivariable analyses between in-hospital adverse drug events (ADEs) and patient characteristic.

\begin{tabular}{|c|c|c|c|c|c|c|c|c|c|}
\hline & & \multirow{2}{*}{$\begin{array}{c}\text { In-hospital ADE } \\
\text { n (\%) }\end{array}$} & \multirow{2}{*}{$\begin{array}{l}\text { Without ADE } \\
n(\%)\end{array}$} & \multicolumn{3}{|c|}{ Bivariable analysis } & \multicolumn{3}{|c|}{ Multiple logistic regression } \\
\hline & & & & p-value & OR & $95 \% \mathrm{Cl}$ & p-value & OR & $95 \% \mathrm{Cl}$ \\
\hline Age in years (ref.: <65) & $\geq 65$ & $9,458(56.7)$ & $7,212(43.3)$ & $<0.001$ & 1.69 & $1.62-1.77$ & $<0.001$ & 0.69 & $0.65-0.73$ \\
\hline Gender (ref.: Male) & Female & $8,679(48.1)$ & $9,347(51.9)$ & $<0.001$ & 0.86 & $0.82-0.89$ & 0.111 & 1.06 & $0.99-1.11$ \\
\hline Type of admission (ref.: Urgent) & Planned & $4,623(39.8)$ & $7,007(60.2)$ & $<0.001$ & 0.54 & $0.51-0.56$ & 0.990 & 1.000 & $0.93-1.107$ \\
\hline Type of treatment (ref.: Surgical) & Medical & $13,179(52.7)$ & $11,813(47.3)$ & $<0.001$ & 1.49 & $1.42-1.57$ & $<0.001$ & 1.29 & $1.12-1.38$ \\
\hline \multicolumn{10}{|l|}{ Principal diagnosis } \\
\hline 486 (ref.: No) & Yes & 995 (66.9) & $492(33.1)$ & $<0.001$ & 2.09 & $1.87-2.33$ & $<0.001$ & 1.33 & $1.17-1.52$ \\
\hline 581.1 (ref.: No) & Yes & $699(86.3)$ & $111(13.7)$ & $<0.001$ & 6.52 & $5.33-7.98$ & $<0.001$ & 15.75 & $12.76-19.45$ \\
\hline 428.0 (ref.: No) & Yes & $571(69.5)$ & $251(30.5)$ & $<0.001$ & 2.32 & $2.00-2.69$ & 0.302 & 1.099 & $0.92-1.32$ \\
\hline 205.00 (ref.: No) & Yes & 462 (98.5) & $7(1.5)$ & $<0.001$ & 67.79 & $32.12-143.04$ & $<0.001$ & 18.63 & $8.71-39.85$ \\
\hline 434.91 (ref.: No) & Yes & $440(63.7)$ & $251(36.3)$ & $<0.001$ & 1.77 & $1.52-2.07$ & 0.065 & 0.833 & $0.69-1.01$ \\
\hline 038.9 (ref.: No) & Yes & $311(76.6)$ & $95(23.4)$ & $<0.001$ & 3.32 & $2.63-4.18$ & $<0.001$ & 0.53 & $0.40-0.71$ \\
\hline Secondary diagnosis [M (SD)] & & $11.7(7.1)$ & $3.9(4.3)$ & $<0.001$ & 1.31 & $1.30-1.32$ & $<0.001$ & 1.27 & $1.26-1.28$ \\
\hline $\begin{array}{l}\text { Duration of hospitalization in days } \\
\text { [M (SD)] }\end{array}$ & & $22.6(29)$ & $6.4(10.3)$ & $<0.001$ & 1.11 & $1.10-1.12$ & $<0.001$ & 1.06 & $1.06-1.06$ \\
\hline
\end{tabular}

95\% Cl: 95\% confidence interval; M: mean; OR: odds ratio; Ref.: reference category; SD: standard deviation. 
Regarding the number of hospitalization days, we also observed that these had increased, so had the probability of the occurrence of adverse events $(\mathrm{OR}=1.06 ; \mathrm{p}<0.001)$.

\section{Association between in-hospital ADE, mortality, and duration of stay}

The episodes of in-hospital ADEs, in the bivariable analysis, showed a proportion of deaths significantly higher when compared with episodes with no ADE (9.6 vs. 4.5; $\mathrm{p}<0.001)$. However, in the multivariable analysis (multiple logistic regression), we did not observe an association between inhospital ADE and increased mortality $(\mathrm{OR}=0.73 ; \mathrm{p}<0.001)$.

Regarding the duration of stay, we observed that in-hospital ADE episodes are linked to a much higher mean of hospitalization days, when compared with episodes with no events (22.6 and 6.4 days, respectively; $\mathrm{p}<0.001$ ). In the multivariable analysis (linear regression), we determined that in-hospital ADE episodes were independently associated with an increase on the duration of stay of 8.18 days $(\mathrm{B}=8.18 ; \mathrm{p}<0.001)$.

\section{Discussion}

The study of 3,041,443 hospitalization episodes, registered for the period under analysis, revealed that $17,213(0.6 \%)$ showed at least one ADE within the in-hospital framework. Since most available studies based on administrative data do not differentiate between the events present at the time of admission and the ones occurring within the hospital framework, it is difficult to make a comparison. On the one hand, the studies available used different methodologies, different populations, and different ICD codes to identify in-hospital ADEs.

However, this study's results were similar to the one carried out in Australia by Parikh et al. 7, which showed a $0.7 \%$ in-hospital ADE frequency.

The studies from Amelung, et al. 4 and Rottenkolber et al. 19 showed a higher percentage of inhospital ADEs (6.6\% and 3.8\%, respectively). In the case of the study by Amelung et al. 4 , the authors considered that the high frequency of events was associated with the fact that the study's period covered a stage in which the encoding quality was strongly connected to German diagnosis related groups-based reimbursement. Regarding the study by Rottenkolber et al. 19, the in-hospital ADE frequency was obtained through a secondary diagnosis, which may result in higher results because the secondary diagnosis was already present at the moment of admission.

Other studies carried out in different countries also showed a higher ADE frequency, between $3.22 \%$ and $6.28 \% 5,20$, but these studies included both the ADE present at the time of admission and the in-hospital ones.

The most recent Portuguese studies, based on administrative data, showed an ADE frequency of between $1.46 \%$ and $1.88 \% 10,11,21$, but they also did not differentiate between the ADE present at the time of admission and the in-hospital one.

In this study, we observed an increased in-hospital ADE frequency: from $0.41 \%$ in 2013 to $0.65 \%$ in 2015. Nevertheless, this situation must be carefully analyzed because these results may reflect a real increase in the in-hospital ADE frequency, but they may also be associated with greater awareness of hospitals about the patients' safety and, subsequently, better practice regarding the recording and encoding of these events. In a study carried out at nine Portuguese acute care hospital centers 9 , it was observed that the adverse event frequency was higher in the accredited hospitals (13.7\% vs. $11.2 \%)$. A reasonable explanation for these results, according to the authors, may be associated with the fact that the accredited hospitals display a greater awareness of the patient's safety and have a systemic practice of data recording and analysis.

Regarding the nature of the events, we determined that $99.4 \%$ of the E-codes were associated with ADR and $0.6 \%$ with AP. These results are not surprising and are in line with the study by Hougland et al. 22, which showed that the codes associated with AP were more prone to detect the ADE caused at the moment of admission than the ones which occurred within an in-hospital framework, contrary to the codes associated with ADR. 
The huge difference between the AP and ADR E-code frequency may reflect the reality of the in-hospital setting or may be associated with several reasons, among which are under-recording and under-encoding.

According to Wachter 23 , records of adverse events may vary in accordance with the institutional culture (punitive or not) and with the individual responsibility of each professional.

AP E-codes are associated with drug errors that may be prevented, while ADR E-codes are not always preventable 16. This difference at the level of an adverse event's prevention could influence the recording/notification of clinical records of the events which occurred.

Regarding the class of drugs associated with in-hospital ADEs, we observed that the antineoplastic/immunosuppressant drugs were among the most frequent causes of events, similar to other studies carried out at a national and international levels 4,5,10,18. Antibiotics, adrenal cortical steroids, anticoagulants, and diuretics not elsewhere specified were also included among the five most frequent causes of ADEs. Similar results were found by several studies carried out in the last five years 5,7,8,10,24.

A possible explanation for these results may be associated with the evidently known effects deriving from the toxicity of these drugs - for instance, antineoplastic drugs and neutropenia, steroids and hyperglycemia, anticoagulants and haemorrhage 5. Clarity about adverse reactions to these drugs may facilitate the recording of events and the encoding process 5.

\section{Population characteristics associated with the occurrence of in-hospital ADEs}

Age groups of 65 years and older showed a higher frequency of in-hospital ADEs, similar to other international and national studies 3,5,7,8,10,11,24. However, in the multivariable analysis, we observed that age was not an independent risk factor in the occurrence of these events. A possible explanation for this result is the fact that age itself is not a risk factor for the occurrence of these events, but rather all the characteristics associated with older patients are risk factors. Older patients become a particularly vulnerable group for the occurrence of ADEs because, due to the natural physiological alterations associated with old age, there is a higher possibility of suffering from a higher number of comorbidities and severe illnesses, leading to the need to receive multiple treatments (highly complex in certain situations), polymedication, and to remain hospitalized for long periods 25,26,27,28,29.

The aging population and the increase of associated comorbidities, as well as increased treatment complexity and non-adjustment of the available funds for the exigencies of the health domain, establish a new potential risk for mistakes and harm to the patients and, subsequently, a challenge for the patient's safety 25. Given these facts, it is clear that health professionals and administrators need to be particularly focused on ADE prevention strategies for this population subgroup.

While analyzing patients' characteristics associated with the occurrence of in-hospital ADEs, we also observed that as the number of secondary diagnoses (complications and/or comorbidities) grew, so did, independently, the probability of in-hospital ADEs. These results are in line with several studies identifying a link between multiple comorbidities and the occurrence of ADEs 5,10,11. On the other hand, the existence of a larger number of complications and/or comorbidities is also associated with multiple medications, which, in turn, is also a risk factor for the occurrence of ADEs 3,24.

In this study, we verified that an increase in the duration of stay at hospital is independently associated with a greater probability for the occurrence of in-hospital ADEs. These results are in line with a meta-analysis carried out by Laatikainen et al. 3 for the period between 2000 and 2016, in which the increase of the periods of stay was identified as one of the main risk factors for the occurrence of ADEs. Hauck \& Zhao 30, when analyzing the risk factors and the incidence of adverse events, also observed that the duration of stay increased the possibility of adverse events at magnitudes comparable with other risk factors, such as age, urgent admission, or multiple comorbidities.

\section{Association between in-hospital ADE, mortality, and duration of stay}

In-hospital ADE episodes showed a significantly higher mortality rate when compared with episodes with no ADE (9.6\% vs. 4.5); however, in logistic regression we did not observe any association between the events and increased mortality $(\mathrm{OR}=0.73)$. Similar results were found by the Portuguese study led by Sousa Pinto et al. 11, in which, when comparing the mortality proportion for episodes with and 
without ADE according to the characteristics of the patients and of the episodes, confirmed that the mortality was lower in the group with ADEs.

These results, regarding the association between in-hospital ADE and mortality, contrast with the results found in other studies based on clinical record review which show an association between inhospital ADEs and the mortality increase 31,32 .

A possible explanation for the results of this study may be related to the fact that the most frequent events are not the most severe or that there is an under-recording and/or under-encoding of the most severe events. In the available BHMH data, there was no data about the severity of the encoded events; therefore, the proportion of the severe events encoded is unknown. On the other hand, the causes of death are also unknown, making it impossible to understand the death proportion associated with in-hospital ADEs.

Regarding the duration of hospitalization, we observed that in-hospital ADEs had a significant impact on the duration of stay and, subsequently, on the hospitals' efficiency, because the presence of these types of events was directly associated with an increase of the duration of stay to 8.18 days with statistical significance. These results are similar to the results of Parikh et al. 7 , which showed that the duration of stay was higher than seven days for patients presenting in-hospital ADEs. In other published studies, it was also verified that the ADE leads to an extension of the duration of stay from 1.7 to 6.7 days $4,5,8,10,11$. This finding is extremely important because any increase in the duration of stay entails financial losses for the hospital, in addition to the personal and social impact for the patients and their families. Nevertheless, we cannot exclude the possibility of an extended duration of stay being at the origin of the occurrences of in-hospital ADEs.

This study presents some limitations; therefore, the results must be considered carefully. Firstly, there is incomplete information and possible filing errors within the BDMH. Secondly, one must consider the non-identification of some in-hospital ADEs, related to under-recording and underencoding problems. Thirdly, there is a lack of specific data in the BDMH, which could help explain some results found - specifically, the severity of the episodes, the severity of the ADEs encoded, and the events that could be prevented. Another limitation is the fact that this study does not include the potential number of medications confounder in the regression analysis. But it is well known that the number of medications is a consequence of the number of secondary diagnoses as well as the primary diagnosis and type of treatment. We have included all of these other variables in the multivariable regression model allowing us to conclude that some primary diagnosis as well as bigger number of secondary diagnoses and medical treatment are associated with more adverse events.

However, this study also presents strong points; of particular note is the analysis of the ADEs occurring during hospitalization, at a national level, for a period of three years. In addition, some strategies were adopted to reduce the effect of eventual biases of other independent variables. In particular, several multivariable analyses were carried out to identify the characteristics of the population associated with the occurrence of in-hospital ADEs and to analyze the association of these events with mortality and duration of stay.

Even though not all in-hospital ADEs may be prevented, this study contributes to improving the information available on in-hospital ADEs at a national level, therefore representing a base of knowledge to support the decision-making process of the hospital administrators and health professionals concerning the prioritization of resources and the targeting of specific strategies for each risk group.

The strategies emerging from different international organizations are consensual in their consideration that in order to minimize adverse events, it is crucial to improve procedures, use technology, and build an organization culture of patient safety 33,34 . In addition to the need for hospitals to be more efficient in implementing safety procedures aiming at preventing adverse events, it is also crucial to efficiently manage the duration of hospitalization.

For a better understanding of this issue, this study also reinforces the need to investigate, in detail, some areas, among which we highlight: analyzing preventable ADEs occurring within the in-hospital framework and their impact on the hospitals' effectiveness and efficiency, analyzing in which phase of the drug's circuit the preventable ADE occurs, and analyzing the severity level of the encoded inhospital ADEs and their association with mortality. 


\section{Conclusions}

This was the first study based in Portuguese hospital morbidity database that distinguishes between ADE present on admission and those occurring during hospital stay, with the application of the variable encoded PAA.

In this study, we observed that 17,213 (0.6\% of the total) of all Portuguese hospitalizations occurring between 2013 and 2015 presented at least one occurrence of in-hospital ADEs. These episodes were independently associated with an increase in the duration of hospitalization.

Even though this study is only a small contribution to a large problem, in our view, it may help assist hospital administrators and health professionals to prioritize resources and target interventions for each risk group, aiming to minimize adverse events and the resulting clinical and financial consequences.

\section{Contributors}

M. Vitorino and P. Sousa conceived the idea presented, designed and performed the study, contributed to the analysis of the results, discussions and to the writing of the final version of the manuscript. P. Aguiar gave statistical advise, contributed to the analysis of the results, discussions and to the writing of the final version of the manuscript. P. Aguiar and P. Sousa helped supervising the research and paper review.

\section{Additional informations}

ORCID: Mavilde Vitorino (0000-0001-9238-3261); Pedro Aguiar (0000-0002-0074-7732); Paulo Sousa (0000-0001-9502-6075).

\section{Acknowledgments}

The authors would like to thank the Portuguese Health System Central Administration (ACSS) for providing administrative database.

\section{References}

1. World Health Organization. Conceptual framework for the international classification for patient safety: version 1.1. Final technical report, January 2009. https://www.who.int/ patientsafety/taxonomy/icps_full_report.pdf (accessed on 02/Nov/2018).

2. World Health Organization. Planning for the global patient safety challenge on medication safety. https://www.who.int/patientsafety/ medication-safety/planning-consultation/en/ (accessed on 05/Oct/2018).

3. Laatikainen O, Miettunen J, Sneck S, Lehtiniemi H, Tenhunen O, Turpeinen M. The prevalence of medication-related adverse events in inpatients: a systematic review and meta-analysis. Eur J Clin Pharmacol 2017; 73:1539-49.

4. Amelung S, Meid AD, Nafe M, Thalheimer M, Hoppe-Tichy T, Haefeli WE, et al. Association of preventable adverse drug events with inpatients' length of stay: a propensity-matched cohort study. Int J Clin Pract 2017; 71:e12990.

5. Poudel DR, Acharya P, Ghimire S, Dhital R, Bharati R. Burden of hospitalizations related to adverse drug events in the USA: a retrospective analysis from large inpatient database. Pharmacoepidemiol Drug Saf 2017; 26:635-41.

6. Martins ACM, Giordani F, Rozenfeld S. Adverse drug events among adult inpatients: a meta-analysis of observational studies. J Clin Pharm Ther 2014; 39:609-20.

7. Parikh S, Christensen D, Stuchbery P, Peterson J, Hutchinson A, Jackson T. Exploring in-hospital adverse drug events using ICD-10 codes. Aust Health Rev 2014; 38:454-60.

8. Weiss AJ, Elixhauser A. Characteristics of adverse drug events originating during the hospital stay, 2011: statistical brief \#164. http:// www.ncbi.nlm.nih.gov/pubmed/24354026 (accessed on 03/Sep/2018).

9. Sousa P, Uva AS, Serranheira F, Uva MS, Nunes C. Patient and hospital characteristics that influence incidence of adverse events in acute public hospitals in Portugal: a retrospective cohort study. Int J Qual Health Care 2018; 30:132-7. 
10. Scripcaru G, Mateus C, Nunes C. Adverse drug events: analysis of a decade. A Portuguese case-study, from 2004 to 2013 using hospital database. PLoS One 2017; 12:e0178626.

11. Sousa-Pinto B, Marques B, Lopes F, Freitas A. Frequency and impact of adverse events in inpatients: a nationwide analysis of episodes between 2000 and 2015. J Med Syst 2018; 42:48.

12. Si S-L, You X-Y, Liu H-C, Huang J. Identifying key performance indicators for holistic hospital management with a modified DEMATEL approach. Int J Environ Res Public Health 2017; 14:934.

13. Rafter N, Hickey A, Condell S, Conroy R, O'Connor P, Vaughan D, et al. Adverse events in healthcare: learning from mistakes. QJM 2015; 108:273-7.

14. Maass C, Kuske S, Lessing C, Schrappe M. Are administrative data valid when measuring patient safety in hospitals? A comparison of data collection methods using a chart review and administrative data. Int J Qual Health Care 2015; 27:305-13.

15. Goldman LE, Chu PW, Osmond D, Bindman A. The accuracy of present-on-admission reporting in administrative data. Health Serv Res 2011; $46(6$ pt 1):1946-62.

16. Hart A, Ford B. Supplementary classification of external causes of injury and poisoning (E800-E999). https://www.optum360coding. com/upload/pdf/IHH07/IPHY.pdf (accessed on 15/Apr/2018).

17. Miguel A, Marques B, Freitas A, Lopes F, Azevedo L, Pereira AC. Detection of adverse drug reactions using hospital databases: a nationwide study in Portugal. Pharmacoepidemiol Drug Saf 2013; 22:907-13.

18. Salmerón-García A, Cabeza Barrera J, Vergara Pavón MJ, Román Márquez E, Cortés de Miguel S, Vallejo-Rodríguez I, et al. Detection of adverse drug reactions through the minimum basic data set. Pharm World Sci 2010; 32:322-8.

19. Rottenkolber D, Hasford J, Stausberg J. Costs of adverse drug events in German hospitals: a microcosting study. Value Health 2012; 15:868-75.

20. Stausberg J. International prevalence of adverse drug events in hospitals: an analysis of routine data from England, Germany, and the USA. BMC Health Serv Res 2014; 14:125.

21. Marques B, Sousa-Pinto B, Silva-Costa T, Lopes F, Freitas A. Detection of adverse events through hospital administrative data. In: Rocha A, Correia A, Adeli H, Reis L, Costanzo $\mathrm{S}$, editors. Recent advances in information systems and technologies. Berlin: Springer, Cham; 2017. p. 825-34.

22. Hougland P, Nebeker J, Pickard S, Van Tuinen M, Masheter C, Elder S, et al. Using ICD-9-CM codes in hospital claims data to detect adverse events in patient safety surveillance. http:// www.ncbi.nlm.nih.gov/pubmed/21249878 (accessed on 18/Jul/2018).
23. Wachter RM. Personal accountability in healthcare: searching for the right balance. BMJ Qual Saf 2013; 22:176-80.

24. Mihajlovic S, Gauthier J, MacDonald E. Patient characteristics associated with adverse drug events in hospital: an overview of reviews. Can J Hosp Pharm 2016; 69:294-300.

25. Yu A, Flott K, Chainani N, Fontana G, Darzi A. Patient safety 2030. https://www.imperial. ac.uk/media/imperial-college/institute-ofglobal-health-innovation/centre-for-healthpolicy/Patient-Safety-2030-Report-VFinal.pdf (accessed on 18/Nov/2018).

26. Pedrós C, Quintana B, Rebolledo M, Porta N, Vallano A, Arnau JM. Prevalence, risk factors and main features of adverse drug reactions leading to hospital admission. Eur J Clin Pharmacol 2014; 70:361-7.

27. Long SJ, Brown KF, Ames D, Vincent C. What is known about adverse events in older medical hospital inpatients? A systematic review of the literature. Int J Qual Health Care 2013; 25:542-54.

28. Onder G, Liperoti R, Fialova D, Topinkova E, Tosato M, Danese P, et al. Polypharmacy in nursing home in Europe: results from the SHELTER study. J Gerontol A Biol Sci Med Sci 2012; 67:698-704.

29. Wu C, Bell CM, Wodchis WP. Incidence and economic burden of adverse drug reactions among elderly patients in Ontario Emergency Departments. Drug Saf 2012; 35:769-81.

30. Hauck K, Zhao X. A structural equation model of adverse events and length of stay in hospitals. Melbourne: Department of Econometrics and Business Statistics, Monash University; 2010. (Working Paper, 04/10).

31. Pardo Cabello AJ, Del Pozo Gavilán E, Gómez Jiménez FJ, Mota Rodríguez C, Luna Del Castillo JD, Puche Cañas E. Drug-related mortality among inpatients: a retrospective observational study. Eur J Clin Pharmacol 2016; 72:731-6.

32. Mouton JP, Mehta U, Parrish AG, Wilson DPK, Stewart A, Njuguna CW, et al. Mortality from adverse drug reactions in adult medical inpatients at four hospitals in South Africa: a crosssectional survey. Br J Clin Pharmacol 2015; 80:818-26.

33. World Health Organization. Medication without harm: global patient safety challenge. Geneva: World Health Organization; 2017.

34. Institute for Healthcare Improvement. SP 100: introdução à segurança do paciente. http://app.ihi.org/lmsspa/\#/a5d865d5-9c8d4db8-977f-8d8600cba5bf (accessed on 18/ Nov/2018). 


\section{Resumo}

O estudo teve como objetivos analisar os eventos adversos a medicamentos (EAMs) em hospitais públicos de Portugal e a associação com mortalidade hospitalar e tempo de internação. Foi analisada uma base de dados administrativos com registros de todas as internações em hospitais públicos portugueses entre 2013 e 2015. Os EAMs foram identificados com o uso dos códigos E850-858.9 e E930-949.9 da CID-9-MC. Identificamos todos os episódios com registro de EAM hospitalar e comparamos com uma amostra aleatória de um número igual de episódios, sem registro de eventos. Foram analisados 3.041.443 casos, dos quais 60.521 apresentavam pelo menos um EAM, das quais 17.213 ocorreram no contexto hospitalar. As classes de drogas mais associadas aos EAMs foram antineoplásicos/imunossupressores, antibióticos e corticosteroides. As características dos pacientes mais associadas aos EAMs (todas com $p<0,001)$ foram internações pela clínica médica $(O R=1,29)$, diagnóstico de leucemia mieloide $(O R=18,63)$, síndrome nefrótica $(O R=15,75)$ ou pneumonia $(O R=1,33)$, número maior de diagnósticos secundários $(O R=1,27)$ e maior tempo de internação $(O R=1,06)$. As hospitalizações com registro de EAM hospitalar mostraram mortalidade significativamente mais elevada $(9,6 \%$ vs. 4,5$) e$ maior tempo de internação (22,6 vs. 6, 4 dias). Os EAMs mostraram associação direta com o tempo de internação hospitalar, aos 8,18 dias. O estudo traz contribuições interessantes relacionadas às classes farmacológicas mais frequentes e às características dos pacientes que podem influenciar a frequência de EAMs nos hospitais públicos portugueses e a consequente carga de morbidade.

Eventos Adversos; Classificação Internacional de Doenças; Hospitalização

\section{Resumen}

Los objetivos del estudio fueron analizar eventos adversos con medicamentos (EAMs) en hospitales públicos portugueses, así como su asociación con la mortalidad y la duración de la hospitalización. Analizamos una base de datos administrativa, que contenía el registro de todas las hospitalizaciones que se produjeron en hospitales públicos portugueses desde 2013 a 2015. Los EAMs fueron identificados usando los códigos E850-858.9 y E930949.9 desde CIE-9-MC. Identificamos todos los episodios registrados de EAMs en hospitales y los comparamos con una muestra aleatoria de un número igual de episodios sin eventos registrados. Se analizaron un total de 3.041.443 de casos, 60.521 presentaron al menos un EAM de los 17.213 que se produjeron en un contexto hospitalario. Los tipos de medicamentos más frecuentes, asociados con EAM, fueron los antineoplásicos/inmunosupresores, antibióticos y esteroides. Las características del paciente, asociadas con una ocurrencia mayor de eventos adversos con medicamentos en hospitales, (todos con $p<0,001)$ fueron: admisiones médicas $(O R=1,29)$; diagnóstico de leucemia mieloide $(O R=18,63)$, síndrome nefrítico $(O R=$ $15,75)$ o neumonía $(O R=1,33)$; un alto número de diagnósticos secundarios $(O R=1,27)$, asi como una duración mayor en el ingreso hospitalario $(O R=1,06)$. Las hospitalizaciones con registros de EAMs en hospitales presentaron una mortalidad significativamente más alta (9,6\% vs. 4,5), así como la duración de la hospitalización (22, 6 vs. 6, 4 dias). Los EAMs mostraron estar directamente asociados con el incremento en los ingresos hospitalarios a partir de los 8,18 días. Este estudio añade algunos planteamientos interesantes, relacionados con los tipos de medicamentos más frecuentes $y$ características de los pacientes, que pueden influenciar en la frecuencia de EAMs en hospitales públicos portugueses, así como también en la carga de las lesiones resultante de los mismos.

Evento Adverso; Clasificación Internacional de Enfermedades; Hospitalización
Submitted on 20/Mar/2019

Final version resubmitted on 20/Aug/2019

Approved on 03/Sep/2019 